\title{
El feminismo como crítica filosófica
}

\author{
NEUS CAMPILLO
}

Universidad de Valencia

Voy a centrarme en el concepto de "crítica» como noción clave, tanto en una teoría de la modernidad como de la racionalidad, y calibrar la importancia que tiene para el feminismo. Mi punto de partida es que el feminismo es, fundamentalmente, "crítica filosoficam. Y lo es, aparte de ser otras muchas cosas: una teoría política, una propuesta para la emancipación de las mujeres, un movimiento reivindicativo, una revalorización de las mujeres como género, una afirmación del sujeto femenino, de las mujeres como sujetos, etc. Sin embargo, lo que le confiere un lugar teórico relevante, a tener en cuenta necesariamente en filosofía, es su carácter de crítica. En Hacia una. crtica de la razón patriarcal" se dilucidaba el punto central. Volver sobre su planteamiento e intentar situar el problema de la teoria feminista desde una perspectiva de teoría de la modernidad podría ser un objetivo fructifero.

\section{Crítica como articulación de razón y libertad}

La complejidad de la noción de wcriticas apunta a un significado especifico que cambió el original y etimológico. El significado de critica, que acostumbraba a ser negativo (reprobación, enumeracion de errores, etc.), sufre un giro desde Kant y "critica" va a significar exactamente una concepcion de la razón, por lo tanto, implica una teoría de la racionalidad.

La palabra crítica en Critica de la Razón Pura no respondería al signifi- cado de krithein: "aislar", "apartar", "descartar lo particularn." Su significación negativa sólo es posible a partir del significado positivo, afirmativo y específico que Kant introduce. Ya a partir de la crítica del arte del dieciocho comienza el significado de critica como formación de las reglas: legislación, destacar lo universal frente a lo particular. "Critica" es "la posición de aquello que debe ser puesto de antemano como lo determinante y lo decisivo en toda posición. Crítica de la Razón Pura no es tanto criticar la razón como delimitar su esencia decisiva y particular». Eso supone hacer hincapié en el sentído de la Arquitectónica de la Razón y es lo que hace posible que la filosoff́a sea "teleología", lógica de los fines, de la razón humana y el filosofo «legislador de la razón».

La crítica define la razón e indica la estructuración interna de la misma, «bosqueja» el «trazo previo de la razón pura" y pone los límites a sus diferentes ámbitos. Crítica es el proyecto de la razón que mide y traza los lírnites mediante los principios, no mediante los hechos, ni mediante la determinación de propiedades. Pero el interés teórico de la razón no es suficiente para poder dilucidar las cuestiones del conocimiento teórico mismo. Un interés teorico exclusivamente paralizaría a la razón en una constante situación antinómica, haciéndola incapaz de superar las controversias en las que dogmatismos y escepticismos nos han sumido ahora, como siempre, incapaces de salir del reino de la perplejidad. 
Como únicamente desde el "interés practicon es capaz la razon de avanzar en tales controversias, la identidad de razón-voluntad, el que la razón sea práctica, es lo que hace posible que en la autorreflexión un conocimiento, por mor del conocimiento, coincida con el interés por la emancipación. La realización de la reflexión se sabe como movimiento de la emancipación y solo el interés cognoscitivo emancipatorio hace posible, al conectarse con la reflexión, que los intereses cognoscitivotécnico y práctico sean comprendidos como intereses del conocimiento. ${ }^{3}$

Al definir la noción de "critica" como la unión de conocimiento e interés se producen dos consecuencias: la delimitación entre un interés puro de la razón y un interés empírico, o patologico, y la posibilidad de que "critica" y "libertad" se articulen. La base del interés empírico es la naturaleza, y presupone una necesidad, la voluntad está al servicio de la inclinación y la razón es sólo el conjunto de reglas prácticas para satisfacerla, es decir, es instrumental. Por el contrario, el fundamento del interés puro es la misma razón, que despierta una necesidad y la voluntad entonces sólo depende de los principios de la razón. De esa manera la "crítica", como la unidad de "conocimiento" e uinteres", permite el interés por la emancipacion.

Que el fundamento de la teoría de la racionalidad sea trascendental, o historico, es una discusión interna a la propia filosofía moderna, pero que se vincule a la modernidad está fuera de toda discusión ya que la teoría de la racionalidad, desde Descartes, no puede separarse de una teoría de la modernidad. Es esa implicación mutua lo que hace posible el surgimiento de una nueva caracteristica en la noción de crítica: el sentido marxiano de que critica es xla autoclarificación de las lu- chas y anhelos de una épocas, sentido que introduce la vinculación de la critica con una teoría de la sociedad. Cuando una teoría de la sociedad se propone como crítica se está asumiendo, de entrada, que no se está de acuerdo con la sociedad existente $y$ que se pretende construir una nueva. Si se me permite, se pretende utransformar el mundon. No significa que se den las recetas de cómo tiene que ser esa sociedad; significa que se reflexiona sobre la misma praxis que aúna los esfuerzos del cambio.

Al unir "conocimiento" e "interés" en la noción de crítica, ésta se convierte en una noción que es hilo conductor de los fines de la razón. Sin embargo, eso no significa que esos intereses sean determinados contenidos ya que la articulación de ucríticas con la noción de "libcrtad" nos permite eliminar cualquier predeterminación de fines. ${ }^{4}$

El tema de la razón se convierte en la modernidad en el tema de la sociedad misma; que una teoría de la racionalidad se coimplique con una teoría de la modernidad significa que la critica incluye, al mismo tiempo, una teoría de la razón y una teoria de la sociedad. Todo ello supuso recoger la tradición crítica en su pleno y positivo sentido y significa pensar desde la raíz los límites que la propia crítica ha podido representar. Como consecuencia, la crítica de la razón dogmática se convierte, a su vez, en objeto de crítica desde diferentes ángulos: como razón instrumental y como razón patriarcal. La teoría crítica de la Escuela de Frankfurt y el feminismo ilustrado llevan a cabo la crítica de ambos aspectos, el cosificador-instrumental y el sexista representando, a su vez, un avance en la noción de crítica.

Ese pensar desde la raíz, esa metacritica también significa que la propia complejidad de la razón evidencia en 
su arquitectura los diferentes ámbitos como articulados; es, en ese sentido, en el que se apela a la unidad de la razón en sentido kantiano, una y otra vez. Sin embargo, desde el principio, se ha tratado de una unidad problematica y en construcción, dependiendo de los fines de la razón, fines que no pueden separarse de la libertad, lo que hace que no estén predeterminados. Además, la complejidad no es sólo de niveles internos a la estructuración de la razón, lo es también del propio proceso de diferenciación de la sociedad. Proceso de racionalización social y cultural que se ha caracterizado por niveles formales de complejidad, cada vez mayores, que han configurado a la razón como razón instrumental, como dominadora de la naturaleza. Al configurarse así, a través del proceso cultural y social de la modernidad, se ha mostrado una relación dialéctica entre dominio de la naturaleza y libertad. Todo el proceso sociocultural y reflexivo de la modernidad representa un proceso de cosificación social y teorica. La teoria, que tiene que ser crítica de una teoria tradicional, cosificada, que se piensa a símisma sólo desde sí misma, tendrá que ser una crítica de esa cosificación. ${ }^{5}$

Como consecuencia, la noción de critica tomará y sintetizará los dos significados mencionados: ser una teoría de la razón, en la que se unen "conocímiento c interés» y ser "la autoclarificación de las luchas y anhelos de una época». Por decirlo de otra manera, use unen el sentido de límites y usos de la razón y el sentido de crítica de la economía política: Kant y Marx (volviendo a Hegel al revés) ${ }^{6}$ Esa "autoclarificación de los anhelos y luchas de una época» da cuenta de la cosificación social de la época y de la cosificación de la misma teoría tradicional: $\mathrm{La}$ necesidad de reconversión de esta en crítica proporciona a la noción de critica una nueva característica: la idea de que la sociedad cosificada no es un producto mecánico sino un producto de la acción humana $y$, como tal, sometible a la actividad guiada por la persecución racional de fines. Por 10 tanto, al comprender que la sociedad cosificada se ha formado por la acción de los hombres se entiende que es producto de una actividad guiada por la persecución racional de fines, pero también, que esa persecución racional de fines ha devenido una persecución racional de medios. Con lo que la realidad social cosificada expresa una falta total de sentido por ser exclusivamente expresion de la racionalidad instrumental. La función de la crítica será dotar de sentido a la realidad social, dotarla de otra lógica que no sea la instrumental. Para lograrlo, no hay que partir de la realidad dada, hay que partir de la misma razón. Corno dice Horkheimer, «La meta que el pensamiento crítico quiere alcanzar, es decir, una situación fundada en la razon, se basa, es cierto, en la miseria presente; pero esa miseria no ofrece por sí misma la imagen de su supresion"? En ese sentido se puede afirmar que la teoría crítica respecto de la realidad social dada «sólo expresa su secreto».

Por lo tanto, el pensar crítico no está al servicio de una realidad de fines ya existentes sino que quiere alcanzar una situación distinta, según los fines de la razón, una situación fundada en la razón. La mayor dificultad para que pueda pensarse la transformación de la sociedad, como posibilidad, y poder desde ahí introducir la crítica de la sociedad cosificada, se encuentra en que la cosificación social abarca el pensamiento identificante de la filosofía y de la ciencia moderna. El pensamiento identificante ha tenido como tarea "borrar la diferencia en el concepto y 
la deducción, borrar lo negativo, lo particular y producir una gran identificación de la pluralidad real en la unidad cognitiva". En ese sentido la razón es cosificante casi por definición quedando vinculada al dominio, al interés del dominio técnico sobre la naturaleza, tanto exterior al sujeto como interior al mismo, al dominio do unos sobre otros. Esa lógica del dominio que la razón ejerce sobre los hombres y las cosas constituye una verdadera dificultad para la crítica y, de no ser superada, convertiría el ejercicio del pensamiento en una mera razón instrumental y la acción humana en una acción de autoconservación."

El verdadero problema para todo pensamiento crítico aparece cuando da cuenta de que en la propia forma del pensamiento se ha reflejado y se transmite lo negativo de la realidad, porque en definitiva "la negatividad del mundo moderno es la traducción social de aquello que como telos secreto operó siempre en la constitución linguística de la realidad históricas. ${ }^{\circ}$ Por lo tanto, entender el dominio, no exclusivamente como un proceso de dominación en una sociedad de intercambio capitalista o, como una dominación patriarcal y sexista, sino como una característica de la forma de racionalidad desde la prehistoria de la razón, incluso desde lo mítico y lo mágico, lleva a mostrar que las dificultades para escapar del dominio son enormes, cuando no imposibles.

Porque, si el pensamiento conceptual mismo es instrumento de control y «telos secreto que operó desde siempre en la realidad lingüística», si el pensamiento conceptual es, por su propia estructura más íntima, el medio de ese espíritu de dominio de la naturaleza exterior e interior del sujeto, entonces "el plexo de obcecación que es la sociedad moderna tiene que apare- cer sin fisuras y la propia idea de ilustrar la Ilustración sobre sí misma tiene que aparecer al cabo como una empresa sin base y sin esperanza. No puede formularse la crítica como crítican." $\mathrm{Y}$, sin embargo, a la radicalidad con que se presenta la cosificación, por parte de los frankfurtianos, se une la paradoja de pensar una racionalidad no cosificada a partir de los potenciales humanos acumulados en el proceso de civilización que pudieran quedar liberados de las cadenas del espíritu dorninador de la naturaleza y mostrar su rostro humano. La empresa se presenta como una empresa vana, puesto que se trata de encontrar un otro mejor en lo malo existente, que opere contra la lógica interna de una ilustración menguada que sólo tiende a una racionalidad de tipo técnico. ${ }^{12}$ Sin embargo, las respuestas del pensar crítico, a esa terrible constatacion, promueven un enriquecimiento de la noción de scriticas que mantiene vivo el programa de la Ilustración y que proporciona una crítica radical. Esa "crítica radical" como "utopía del conocimiento" consistiria en, como Adomo dice en Dialéctica $\mathrm{Ne}$ gativa, allegar mediante el concepto más allá del concepto». Porque "se trata de hacer justicia a lo no-idéntico, a lo inconmensurable, a lo distorsionado por el conocimiento y la práctica dominantes". ${ }^{13}$

Desde el momento en que la crítica introduce la idea de que hay algo más que cosificación y racionalidad instrumental y que, no es sólo la lógica del dominio lo que las forma, sino que también se producen normas de intersubjetividad no coercitiva en las relaciones entre los individuos, en su socialización y en su propia comprension, ${ }^{14}$ desde ese momento, también la crítica introduce la idea de una práctica emancipatoria desde las posibilidades existentes on esa estructuración 
lingǘrstica y social de intercomunicacion. Critica se une ast a libertad, pues, su articulación mutua hace pensar en formas de intersubjetividad no coercitiva que representarían un estado social de autodeterminación. ${ }^{15}$

Ahora bien, desde Kant, al articular la nocion de crítica con la de libertad, en el sentido de que la razón que expresa la crítica es voluntad en una de sus caras, cuando se habla de alcanzar una situación fundada en la razón no es, en absoluto, en el sentido de definir y caracterizar un determinado estado social concreto. Porque la idea de libertad que se piensa desde la noción de critica imposibilita que se defina la sociedad futura: "De cómo será consumido el futuro con el que tiene que ver el pensar crítico, de eso no hay ejemplos semejantesm. ${ }^{16} \mathrm{O}$, por decirlo con las palabras que de forma más precisa han definido esta idea: "En efecto, nadie puede ni debe determinar cual es el supremo grado en el que tiene que detenerse la humanidad ni, por tanto, cuál es la distancia que necesariamente separa la idea y su realización. Nadie puede ni debe hacerlo, porque se trata precisamente de la libertad la cual es capaz de franquear toda frontera predeterminadas. 17

Al articular la noción de crítica con la de libertad parece que se está ya definiendo qué tipo de sociedad es la que se opone a la sociedad cosificada. Está claro que sería una sociedad de seres humanos libres que se opone a la sociedad existente, a tuna sociedad de seres humanos alienados. Pero, en todo caso, se presenta como una idea reguladora para oponer libertad a cosificación.

Ahora analizaré por qué el feminismo es una teoría que se forma como una sintesis de crítica y libertad y c6mo ello es lo que nos permite considerarlo como una teoria crítica. Reco- geré posteriomente la noción de crítica articulada a la de libertad como elemento mediador tanto en la polémica modernidad-postmodernidad, en sentido general, como en la misma polemica, dentro del feminismo, entre el feminismo ilustrado $y$ el feminismo postmoderno.

\section{El feminismo como critica y libertad}

Como he dicho, presentar el feminismo como "crítica filosófica» tiene el sentido de situar la teoría ferninista en el lugar teórico que le corresponde. No es, pues, un ajuste de cuentas con ol saber filosofico transmitido, aunque también. Se trata, sobre todo, de clarificar las interrelaciones del feminismo con el pensar filosófico de la modernidad y romper una lanza, si se me permite la varonil expresión, en favor de ambos. Siendo, como es, una necesidad teórica en el diálogo filosófico actual también es una necesidad personal de autoclarificación, una necesidad casi existencial, aunque en cierta manera ambas constituyen un único objetivo, en realidad, una misma pasión.

Entender el feminismo como "crítica filosóficas significa dar cuenta de que, no sólo no puede prescindir de ser una reflexión sobre la razón y mostrar sus límites desde el genero, sino que además en el feminismo se evidencia la necesidad de pensar, de forma radical, los principios ilustrados que constituyen la actitud de la modernidad. Significa eso porque en esa radicalización y al dar cuenta de los límites de la universalidad de la razón ilustrada se forma como una teorfa que expresa la articulación misma de razón. y libertad, que se expresa, en definitiva, como crítica.

En todas las culturas ha habido discursos sobre hombres y mujeres y sus relaciones, en todas las culturas se ha 
definido a la mujer. Nuestra propia tradición cultural está llena de narraciones sobre las mujeres. Sin embargo, lo que constituye al feminismo como tal es su vinculación con una teoría de la razón y eso se produce en la modernidad. Fundamentar con razones la crítica al prejuicio interesado de la desigualdad de los sexos, del dominio interesado de los hombres sobre las mujeres $y$ argumentar con razones, sin prejuicios, sin galanterías, "l'égalité de deux sexesn, solo pudo hacerse al vincular el problema social de que a la mitad de la especie se le hubieran asignado funciones sociales subordinadas y de servicio a la otra mitad, definiendo a un sexo como dominador del otro sexo, con el problema de legitimar que eso no debía ser así si se pretendía construir la especie como wespecie moral".

Vincular el problema que «la querelle des femmes: ${ }^{13}$ proponía como polemica, entre las distintas concepciones sobre las mujeres, con una teoría de la razón hizo posible que la fórmula «lesprit n'a pas de sexe» - «il ait de Tout sexe" ${ }^{10}$ pudiera, sin desexualizar a los individuos concretos, desarrollar la propuesta formal de la universalidad, desde donde argumentar por la igualdad de todos los miembros de la especie. Esa será la fórmula para atener razones" contra el prejuicio de que está justificado el dominio de un sexo sobre otro, por el sexo mismo, y poder oponer al dominio de la fuerza el poder y la fuerza de la razón. La razón universal puede pensar la igualdad, pero también la diferencia $y$, al hacerlo, une el problema de que cada individuo es distinto de cualquier otro con el de que todos los individuos de la especie son iguales por constituir la especie. Las diferencias genéricas no constituyen fundamento alguno para justificar derechos de la especie.
En ese sentido, la teorfa de la razón como "critica» también del prejuicio sexista, se constituye en el desarrollo del programa de la Ilustración como condicion de posibilidad del feminismo. Eso significa que el feminismo se vincula a la Ilustración no solo históricamente, aunque efectivamente se de esa vinculación histórica. Pero lo que no hay que olvidar es su articulacion teorica. Y es esa articulación teórica la que nos permite pensar la Ilustración como ambivalente: es condición de posibilidad del feminismo y redefinición del patriarcado, al mismo tiempo. La razón ilustrada se desarrolla como razón patriarcal de forma incoherente $y$ paradójica consigo misma y muestra, tambien desde el ángulo de las relaciones entre los sexos, que no sólo es liberadora sino dominadora. Esa especial dialéctica de la Ilustración, ${ }^{21}$ desde el especifico ámbito del dominio patriarcal, fue posible porque al pensar la idea de humanidad y la unidad de la especie como especie moral se la caracterizó como tal desde el derecho de ciudadanía pero, tanto teórica como revolucionariamente, se pensó sólo en los hombres, y además propietarios, como sujetos de ese derecho. ${ }^{21}$ La crítica del feminismo a esa exclusión, la apelación al "buen sentido de la humanidad»,22 la declaración de los derechos de las ciudadanas, lo constituyó en una radicalización de los propios principios ilustrados. ${ }^{23}$ La critica del feminismo argumentaba desde la idea de igualdad, la misma idea de igualdad que el universalismo de la razón habia utilizado como fundamento del contrato social y mostraba así la necesidad de llevarla hasta sus máximas consecuencias y no limitarla La crítica feminista mostraba que sólo desde el prejuicio misógino, que no desde la razón, se podía sostener que se dejara a la mitad de la humanidad en la minoria 
de edad y ser el deleite de la otra mitad. Solo desde el prejuicio sexista se podía sostener que un sexo tenfa que dedicarse a la formación del otro sexo para que pudiera ser ciudadano y constituir la humanidad sólo con la mitad de la especie. ${ }^{24}$

Radicalizar las ideas ilustradas y mostrar sus paradojas constituyen el núcleo del programa feminista. No por casualidad fue una mujer quien expresara la fórmula: «Las luces se critican con más luces». ${ }^{25} \mathrm{Y}$, de la misma manera que el pensamiento crítico diagnosticó esa idea de que el pensamiento cra dominador en su más intima estructuración lingúistica con la que se producía la socialización y culturalización, así también el feminismo desarrolló la idea de que esa cosificación de la razón y la sociedad tenía un dominio especifico: el del sexo.

La teoría feminista se reformulo desde la ontologia ${ }^{26}$ para denunciar que filosóficamente la mujer habfa sido definida como "naturaleza", como la "alteridad absoluta», como "lo Otro", fórmulas todas ellas que podian definir "al segundo sexo" y mostrar que "si no se nace mujer, se llega a serlo", ese "llegar a serlo" estaba mediatizado por lo que se había construido como "mujer» desde el pensar masculino. Beauvoir mostró que "la mujer es para si una concicncia" $y$, con ello, radicalizó, en términos ontológicos, la critica feminista ilustrada de elevar a la mujer al rango de individuo, sujeto de derechos, al rango de ciudadana. Esa radicalización permitió que el feminismo introdujera en la noción de crítica la idea de que lo sexual es un vinculo específico de dominio (wel vínculo que la une a sus opresores no se puede comparar a ningún otron); introdujo la idea de la necesidad de relación con el sujeto del dominio (aes el Otro en una totalidad cuyos dos términos son necesarios el uno al otrom); introdujo la idea de la existencia auténticamente asumida por parte de las mujeres y planteó el problema de las complicidades con la opresión («las mujeres no sólo viven en el patriarcado sino que el patriarcado vive en ellas"). Pero, sobre todo, relacionó la idea del dominio sexual con la de que se definieran las oportunidades del individuo, no en términos de felicidad sino de libertad. Al hacerlo así, la noción de crítica se enriqueció desde el feminismo con la idea de una nueva libertad. Se reinterpretaba en clave existencialista-feminista toda una tradición romántica de la creatividad del individuo. Se trataba de un reto arduo porque, de la misma manera que la libertad ilustrada, en términos de derechos, etc., habia sido negada para las mujeres, también la libertad romántica, desarrollo de todas las potencialidades creativas del individuo, había tenido su particular sexismo, su limitación en lo femenino. Para la misoginia romántica las mujeres no eran individuos creativos que desarrollan su libertad, sino objeto de deseo, para bien o para mal. Sin embargo, también es cierto que, al unirse la concepción romántica del individuo libre y creativo con el racionalismo se defendió que la mujer lograra el estatuto de individuo. Aunque la misoginia romántica había conceptualizado a la mujer como "naturaleza", como "lo absoluto", como ssibila del futuron, si se la buscaba en Oriente como lo no contaminado por la civilización, en contrapartida la unión de racionalismo y romanticismo en el programa de los Mill $^{27}$ representaba un avance $y$ un nuevo reto para el feminismo.

Beauvoir ${ }^{2 s}$ llevó hasta sus máximas consecuencias esta tradición, este reto y reformulo la filosofía feminista en términos de buscar definir a la mujer 
como trascendencia, como libertad. Eso era importante porque se trataba, sobre todo, de abatir las infructuosas polémicas, una y otra vez recurrentes históricamente, sobre la superioridad, inferioridad, e igualdad que chan pervertido todas las discusiones $y$ empezar de nuevon. Ese aempezar de nuevon se hacia uniendo "crítica y libertad» como nociones claves en el pensar feminista.

Sin embargo, a pesar del claro planteamiento de Beauvoir, la astucia de la razón patriarcal impide, una y otra vez, que el crepúsculo en el que Minerva levanta su vuelo sea de color violeta y se han dado, de nuevo, las discusiones en las infructuosas polemicas sobre la superioridad, la igualdad, la diferencia.

\section{Paradojas del feminismo}

Las relaciones entre feminismo y filosofía ponen de manifiesto las tensiones entre ambos, lo cual se muestra también en la actitud del feminismo respecto de la filosofía. Esta actitud conlleva no menos paradojas que las que el pensar filosofico y el discurso ilustrado presentan. Desde los años ochenta estas polémicas se dan de forma muy variada. Sin embargo, voy a centrarme en la discusión tal y como se da en torno al debate modernidad-postmodernidad entre el feminismo ilustrado-igualitario y el feminismo postmoderno. ${ }^{2 y}$

Las reflexiones del feminismo radical-postmoderno sobre las relaciones cntre feminismo y filosofia evidencian las paradojas en las que también cae el feminismo. Ya la división entre un feminismo igualitario, radical y conservador, que se presenta como una división paradigmática de lo que está ocurriendo en el desarrollo de la teoría feminista en la actualidad, adolece de una serie de insuficiencias y caracterizaciones erróneas que es necesario clarificar para poder situarnos respecto de nuestro propio paradigma filosófico.

Interesa, sobre todo, dar cuenta de cómo desde una perspectiva del feminismo radical se acaba afirmando las posibilidades de la razón cuando la base fundamental para la división con el feminismo de la igualdad consiste, al contrario, en una dicotomía insalvable sobre la concepción de la razón. Se hace necesario indagar en la noción de crítica precisamente por ello.

Determinadas tesis del feminismo radical son discutibles: por ejemplo, cuando afiman que ula filosofía difiere de otros discursos en tanto que los elementos que excluye son generalmente asociados con la feminidad".$^{30}$ Lo que es inexacto es que se haya producido una exclusión de los elementos asociados a la feminidad; más bien, lo que se ha producido, y no sólo en la filosofía sino en otros discursos, ha sido algo mucho más complejo: inclusión, pero desvalorizada respecto de lo masculino. Por eso el planteamiento no es exacto. La indagación en las relaciones entre feminismo e ilustración está mostrando cómo, de forma recurrente, se ha pensado la feminidad de todas las maneras posibles, se la ha caracterizado en función de la dicotomía; otra cuestion, o la cuestión es que sea desvalorizada. Sin embargo, cómo deben ser las relaciones ente los sexos es siempre un tema dominante.

El no ver este problema con toda la complejidad que requiere incide negativamente en la apreciación que el feminismo radical hace del que llama feminismo de la igualdad, pero, lo que es teóricamente más grave es la incoherencia que representa dentro del propio feminismo radical que defiende el utilizar los discursos filosóficos 
críticos con la razón, o antiilustrados (o postmodernos) para, partiendo de ellos, construir la propia filosofía del feminismo radical. No tiene pues sentido acusar al feminismo igualitario de hacer lo propio: "se caracteriza, dicen, por adherirse a los valores del pensamiento masculino y patriarcal emparejado con el objetivo de incluir a las mujeres como iguales a los hombres». ${ }^{31} \mathrm{El}$ argumento clave en su crítica al feminismo igualitario es la crítica a Simone de Beauvoir: "Ella reproduce las representaciones hostiles de Sartre de la feminidad en su propia expresión de la opresión de las mujeres, en su discusión de la biología de la hembra y en su explicación del vacio de las mujeres en la trascendencia por las vulnerabilidades del cuerpo femenino. Implica que sólo si las mujeres pueden superar sus cuerpos pueden conseguir la igualdad con los hombres, esto es sólo cuando las mujeres no sean mujeresm. .2

Sin embargo, habría que tener en cuenta que el problema desarrollado por Beaurvoir no se reduce a esa afirmación final, en absoluto. Lo que plantea es el problema de la incardinación de la trascendencia en un cuerpo y ello tiene mayores dificultades en el cuerpo fomenino porque ha sido pensado como un constructo desvalorizado para la trascendencia, no porque ontologicamente sea así. Por lo tanto, si bien es cierto que Beauvoir considera que el cuerpo, como instrumento de nuestra aprehension del mundo, es fundamental para tener aprehensiones distintas $\mathrm{y}$, en este caso, distintas según el sexo, sin embargo, no entiende que el cuerpo constituya un destino inamovible. Sólo por la asunción en una conciencia a través de las acciones puede el cuerpo llegar a ser realidad vivida $y$, en consecuencia, lo biologicosexual ni explica que la mujer haya sido relegada a ser "el Otrow ni tampoco la define.

Otra de las criticas del feminismo radical consiste en rechazar el programa igualitario porque entiende que la defensa de la igualdad entre hombres y mujeres implica, al mismo tiempo, la defensa de la no distinción entre los individuos y ello supondría una "neutralización de lo femeninos. ${ }^{33}$ A ello habría que responder que la idea de igualdad como idea reguladora explicita la universalidad de las normas y leyes con que social y políticamente han de ser tratados los individuos de la especie para, precisamente, ser especie humana ${ }^{34} \mathrm{Ha}$ de envolver, por lo tanto, una neutralización de lo femenino y de lo masculino, de lo negro y de lo blanco. Pero, al mismo tiempo, se mantiene la peculiaridad individual en la que se da el rasgo de genero. Por lo tanto, creo que hay que salir de la polémica clásica de la igualdad-diferencia porque conlleva paralizaciones teóricas y políticas no convenientes para las vindicaciones feministas. La utilización patriarcal de la diferencia ha sido recurrente y aunar los esfuerzos del feminismo para acabar con esa utilización ha de ser tarea prioritaria.

Las acusaciones al feminismo igualitario, en el sentido de que "mantiene el entramado básico de la teoría masculina incuestionado", desconocen que tanto la teoría feminista crítica ilustrada de la actualidad, Nancy Fraser, Seyla Benhabib, Celia Amorós, Amelia Valcárcel, como la clásica, desde Mary de Gournay a Simone de Beawvoir, significan una crítica radical, justo, de ese entramado. Mantener ideales que son también de los varones no significa en absoluto mantener lo masculino como discurso universal. Paradigmático de ello es lo referente a la razón: cuestionarse la masculinidad de la razón cabe haccrlo como razón patriar- 
cal, pero evidenciar y criticar las características patriarcales de la razón no implica abogar por la irracionalidad o el fin de la razón.

Otra de las críticas al feminismo igualitario, por parte del radical, consiste en acusarle de individualismo, alegando que es un subterfugio apelar al individuo para enmascarar bajo un termino aparentemente neutral lo que en realidad es masculino. Pero, habría que decir, que "individuo" no es un termino neutral, precisamente es el contrapunto teórico de la universalidad para poder dar cuenta de las caracteriticas particulares, diferentes. La afirmación de lo particular no significa eliminar lo universal sino ver de qué manera la apelación a la universalidad no significa eliminación de la diferencia.

Pero el punto crucial en el que el feminismo radical es aporético es en el tema de la razón. Su crítica del desarrollo de la razón como masculina introduce la posibilidad de eliminar el discurso mismo de la razon "no hay espacio en los sistemas teoricos para la inclusión de las mujeres", se afirma, mientras que, inesperadamente hay una defensa de la razón y de la filosofla. Es un planteamiento aporético en tanto que la crítica al feminismo igualitario la ha basado en considerar que defiende la razón y el propio discurso filosófico a pesar de ser masculinos. Ahora bien, sus conclusiones son las mismas. Así, por cjemplo, Lloyd argumenta: "La crítica de la razón puesta por muchas feministas puede ser vista como parte de una tradición de autocrítica, una critica sostenida por los mismos filosofos en sus relaciones con el pasado. Mientras que la razón es un concepto dominado masculinamente hasta nuestros días, no hay razón para suponer que las nociones filosóficas de la razón no pueden ellas mismas reformarse de manera que las transforma- ciones compatibles con los principios feministas puedan ellas mismas llegar a formar parte del entramado filosóficon. ${ }^{35}$ Lo cual significa mantener la necesidad de no abandonar la razón ni la filosofía por mucho que ambas se hayan caracterizado por su masculinidad. La tarea del feminismo seria transformar la razón para lograr que fuera genuinamente humana más que una tarea exclusivamente masculina.

La discusión entre un feminismo radical y otro igualitario en este punto deja de tener sentido: parece que la "crítica de la razón patriarcals es el camino. Un programa de crílica feminista que suponía reconstruir-deconstruir la noción de razón que la modernidad habia desarrollado, abogando por un nuevo concepto de razón que fuera nominalista, analítico, no androcéntrico..$^{36}$ La diferencia está en que no se pretende que esa transformación crítica se realice desde un feminismo que indague en lo femenino los fundamentos de la razón, o que busque una razón fundada en lo femenino. Bastante tenemos ya con deconstruir el fundamento masculino. De acuerdo en que se debcrian alterar o transformar las teorías, pero el problema está en qué se entiende por esa transformación. Si se considera que, al ver los límites de las estrategias igualitarias del feminismo liberal individualista, muchas defensoras de la igualdad se convierten en radicales, lo mismo se podría decir respecto de los límites del feminismo de la diferencia cuya utilización patriarcal es evidente. ${ }^{37}$

El problema entre los dos feminismos no radica, pues, en transformar la filosofía. Ambos parecen estar de acuerdo en ello, aunque el así autocalificado feminismo radical, de forma paradójica, representa la muerte de la razón. El problema está en cómo se lleva a cabo esa transformación. Porque el 
programa, en líneas generales, del feminismo radical promueve una filosofía feminista que defienda una opción de racionalidad de acuerdo con una relación estratégica con el feminismo distinta. Se presenta, pues, como un programa que ya no abandona la filosofia sino que pretende transformarla. Su objetivo serfa que las feministas deben negociar una serie de estrategias que no pongan únicamente los principios feministas en términos filosóficos sino que sitúe a la misma filosofia en la transformación feminista. ${ }^{38}$

Según el feminismo radical la transformación de una filosofía feminista abogaría por un perspectivismo que consistiría en ampliar y multiplicar los criterios de lo que es considerado verdadero, racional o válido y que condena a los que lo perciben como discriminatorio. Una filosofia feminista debería ser, según el feminismo radical, la que aceptara todos los discursos como específicos de un contexto manteniendo su posición política propia, ya que entienden que "todos Ios textos hablan desde o representan posiciones particulares dentro de las relaciones de poder ${ }^{39}$ Una filosofia que aceptara la intersubjetividad, entendiendo por tal que «la validez de una teoría no ha de ser juzgada a partir de su adopcion de una forma prefijada sino de acuerdo con sus efectos intersubjetivos, esto es su capacidad para ser comprendida y comunicada por los que ocupan posiciones similares". ${ }^{40}$ Esa interrelación de los discursos está suponiendo, sin explicitarlo, una racionalidad comunicativa y, efectivamente, parte del feminismo igualitario ${ }^{4}$ defendería tal teoria de la racionalidad $y$, por supuesto, no sólo el feminismo. No sería exactamente una novedad desde el feminismo sino que supondría una transformación del concepto de razón que el feminismo asume y amplía.
Respecto de las relaciones sujeto-objeto sucedería otro tanto; porque introducir como característica novedosa desde el feminismo una crítica filosofica como la de transformar las relaciones entre sujeto y objeto de manera que no sean dicotomías excluyentes es desconocer que la mayor parte de la filosofía contemporánea es un esfuerzo constante por romper csa dicotomía.

La característica de oponer estrategia a verdad tampoco sería original porque entraria de lleno en la perspectiva del pragmatismo americano y de R. Rorty en la actualidad.22 Para un modelo estratégico es irrelevante la oposición entre verdad y falsedad, pero, habria que objetar hasta que punto dicho modelo estratégico no cae en la razón instrumental, razón criticada por el feminismo como la propia de la masculinidad en tanto que razón dominadora,

La superación de la dicotomía verdad-falsedad es solo aparente porque se mantiene como programa $y$, además, se dice prescriptivamente "qué debe ser la filosofia feminista» porque no se puede, consideran, dar una definición descriptiva de la misma. Pero lo que debe ser la filosofia feminista implica qué no debe ser $\mathrm{y}$, por lo tanto, cabe esperar en base a qué criterios se prescriben unas y no otras caracteristicas. Es decir, de nuevo paradojicamen. te, se rechaza como programa la búsqueda de la verdad y, al mismo tiempo, se supone, aunque no se explicita, un criterio en base al cual se estable. cen las caracteristicas de lo que debe ser la filosofia feminista.

Lo mismo sucede con otra de las características que el feminismo radical dice que adebe» tener la teoria feminista: las relaciones teoria-práctica. En lugar de una división entre teorfa y práctica, se propugna "la teoría como una forma de práctica textual, concep- 
tual y educacional', 43 Pero esas son propuestas que no son especfficas del feminismo, sino que sencillamente establecen un programa de pluralidad de discursos y prácticas en el que el feminismo radical se insertaría. No se ve por ninguna parte la originalidad del feminismo en ello.

La ultima caracteristica tendría que ver con un proyecto de razón que uampliara el concepto de razón misma en el sentido de no excluir a los otros y de incorporar a su concepto la experiencia; no separándose del cuerpo sino aceptándolo y no distinguiéndose de la vida cotidiana sino conociéndola». ${ }^{44}$ Hay una serie de confusiones entre lo que es la misma relación razón-experiencia y razón-vida porque tampoco es eso una novedad del feminismo. Tanto el vitalismo como las filosofías del mundo de la vida y la sociología de la vida cotidiana han desarrollado estos análisis.

La confusión consiste en que parece que esa propuesta de transformación de la filosofía por el feminismo, que el feminismo radical propone, toma prestados sus presupuestos teóricos del relativismo y el pragmatismo y los reasume. Afirman que su interés no radica tanto en la teoría como en la ocupación de nuevos espacios pero el feminismo ilustrado, el feminismo como crítica, no excluye que esa práctica de nuevos espacios no sea un objetivo. Pero introduce esas prácticas en la reflexion y se preocupa por clarificar si se trata o no de un decisionismo.

Efectivamente la novedad de la filosofia feminista está en la reflexión feminista, y no es ninguna obviedad, aunque lo parezca. Frente a afirmaciones como las que hace el feminismo radical de considerar que «los ideales y aspiraciones universales de la filosofía son masculinos, no humanos intereses ${ }^{45}$ habría que contestar que sólo una filosofia feminista que articule crítica y libertad puede conseguir ideales universales humanos y no sólo masculinos. Pero esa filosofía no tiene que abandonar el ideal de universalidad, antes al contrario, desarrollará ese ideal de tal manera que no sea privativo de lo masculino. Por lo tanto, no hay que cuestionar la universalidad de la razón, sino que sea una universalidad patriarcal y totalizadora.

\section{Critica y libertad como «ethos» de la modernidad}

Insistiría en entresacar todos los aspectos que el programa ilustrado nos propone, reflexionar una vez más sobre la modernidad como una via que da cuenta del marco en el que el feminismo se inserta como "una instancia crítica privilegiadan, ${ }^{46} \mathrm{El}$ programa de la Ilustración fue el desencantamiento del mundo y esa vinculación entre el programa ilustrado y el desarrollo de la modernidad social y cultural es lo que proporciona el marco teoricopráctico del feminismo.

Que el proyecto teorico y emancipatorio de la Ilustración sigue siendo fructífero se constata cuando, incluso, desde perspectivas consideradas como postmodernas, ${ }^{47}$ se desarrolla un programa metodológico vinculado a la misma modernidad. Interesa volver, de nuevo, a la noción de critica y al sentido de libertad como idea reguladora y posibilidad abierta.

La clave de las relaciones entre Ilustración y modernidad es que la Ilustración constituye la actitud misma de la modernidad. El desencantamiento del mundo, la división en esferas autónomas - ciencia, ética, arte- tienen un punto común con el proyecto ilustrado estrictamente filosofico ${ }^{43}$ ¿Qué significa esa actitud de la modernidad? El elemento clave es el de la crítica como 
momento en el que la humanidad pone el uso de la razón sin autoridad y fija, en la razón misma, las condiciones bajo las que es legítimo el uso de la razón. El otro concepto clave es el de libertad. Una práctica de la libertad que respeta y viola la misma realidad es clave para todo proyecto emancipatorio $y$, por lo tanto, también para el feminismo. Se trata de entender que wel valor del presente es indisociable de una desesperada impaciencia para imaginárselo de manera distinta, transformándolo, no destruyéndolon, ${ }^{4}$

En el sentido de Foucault nuestra conexión con la llustración no es una cuestión de elementos doctrinales, sino la reactivación permanente de una actitud, esto es de un ethos filosófico que puede ser descrito como una crítica de nuestra era histórica. Define cierta manera de filosofar porque es «el punto de unión del progreso de la verdad y la historia de la libertad. La Ilustracion como ethos filosófico consiste en un ethos que se caracteriza por «una actitud Ifmites que Foucault expresa como un: tenemos que ir más allá de la alternativa fuera-dentro, «tenemos que estar en las fronteras"..0 Esa caracterización de Foucault del ethos de la llustración tiene un sentido muy directo de encontrar la genesis de su propia propuesta: «una historia ontológica de nosotros mismos», y en tal sentido es destacado por él. Pero es evidente que lo que muestra, y por eso lo hace suyo, es la radicalidad de la propuesta de la actitud filosófica ilustrada, que por eso hacemos nuestra. Esa radicalidad de la propuesta se fundamenta en el sentido de crítica y en el sentido de libertad como lo no prefijado, ni definido, sentido que es claramente kantiano.

La importancia de la actitud filosófica ilustrada para el feminismo estriba en que ese mismo programa de crítica, que analiza y reflexiona sobre los lími- tes, es radicalizado por el feminismo en tanto que este, como crítica de la razón patriarcal, reflexiona sobre los mismos límites del programa ilustrado. El ethos de la modemidad es llevado así a sus maximas consecuencias siguiendo su propio programa. "Hay que transformar la crítica en una critica práctica que toma la forma de una posible transgresión" o "investigando dar nuevo impetu, tan lejos y amplio como sea posible, al trabajo indefinido de la libertad $* .^{51}$

El cuestionamiento que hace Foucault del universalismo de la Ilustración se centra en los aspectos totalizadores y los "proyectos globales" que puede implicar el programa ilustrado. Sin embargo, lo mantiene en tanto que representa la actitud critica que define el proyecto de la modernidad. Ese aspecto es el que interesa poner de manifiesto porque expresa muy claramente cómo no seguir manteniendo programas totalizadores no implica rechazar la actitud de la modernidad definida como articulación de crítica y libertad. ${ }^{52}$

El propio ethos de la modernidad supone rehusar al lado negro de la Ilustración, es decir, a estar en pro o en contra de la Ilustración misma. En ese sentido el planteamiento ha de ser una dialéctica de modernidad y postmodernidad. ${ }^{53}$ en la que, como programa amplio se incluyera el feminismo Si el desarrollo y adquisición de capacidades y lucha permanente han sido las esperanzas del s. XVIII y caracterizan a la sociedad occidental, el problema no radica en eliminar esas esperanzas sino en lograr que se «desconecten de la intensificación de las relaciones de poder ${ }^{54} \mathrm{El}$ proyecto, por lo tanto, es un proyecto inacabado y las propuestas no tienen que ser globalizadoras ni totalizadoras, pero sí críticas y racionales; asi como de transformacio- 
nes especificas respecto de determinadas relaciones de poder y dominio.

Porque sel estado de mayoría de edad de la humanidad" sigue siendo una propuesta desde una dialéctica de modernidad-postmodernidad. Y el programa filosofico del feminismo ilustrado incide en esa propuesta desde lo que significa la radicalización del mismo; para que la igualdad que la universalidad propone se realice desde las perspectivas de una diferencia y unas particularidades que le den sentido. Para que se asuma, una vez más, la idea de libertad sin quedar predeterminado el estado en el que se realizaría "la Constitución justa" porque "no puede ni debe quedar predeterminado ya que se trata de la libertady. .55

Es en ese mismo sentido en el que Foucault afirma: "No sé si se debe decir hoy que la tarea crítica aún supone fe en la Ilustración; yo continúo pensando que esa tarea requiere trabajo sobre nuestros límites, eso es, una paciente labor dando forma a nuestra impaciencia por la libertad. El vacío sueño de la libertad». ${ }^{56}$

«Dar forma, pues, a nuestra impaciencia por la libertad $\$, 57$ buscar una sociedad y un pensamiento no cosificados, sería un presupuesto unificador de los diferentes feminismos La complejidad en la dilucidación de esta cuestión enlaza con la crisis de la racionalidad en general y con lo que se ha llamado la crisis de la modernidad. Por lo tanto es la cuestión y creo que el feminismo debe abordarla porque se relaciona con ella con una relación de coimplicación. Hay que aclarar si la dispersion de los distintos feminismos es, o no, deseable teórica y prácticamente y que planteamientos no dogmáticos ni de razón total se pueden llegar a desarrollar que den cuenta de cuál podría ser esa sociedad y ese pensamiento no patriarcales que el femi- nismo propone. ¿Cuáles son los criterios de normatividad del feminismo? ¿Por qué debe ser la sociedad una sociedad no dominada por la masculinidad, por el patriarcado? Estas cuestiones creo que aun no haciéndose explicitas están contenidas en los diversos feminismos y si lo que pretendemos es la autocomprensión del mismo habrá, si no que aclararlos, al menos explicitarlos. Habría que debatir si es necesario mantener las propuestas de los diferentes feminismos como propuestas antitéticas o si se buscan elementos de confluencia entre ellas. La razón de ver en la articulación de crítica y libertad el elemento de mediación entre los diferentes feminismos está en que son aspectos ineludibles en toda propuesta feminista. Un desarrollo del feminismo en este sentido representaría un claro avance en la superación de la polémica igualdad-diferencia. Ese avance ha de hacerse sin renunciar a la actitud de la modernidad. Es tarea del feminismo como crítica filosofica reflexionar sobre los límites de la llustración por lo que se refiere al problema de la desigualdad de los sexos e indagar en las posibilidades que, al mismo tiempo, presenta el universalismo de la Ilustración para resolver el problema de esa desigualdad.

En ese sentido no suscribiría que "todo vale", o que "nada vale si no se enlaza en un todo". Lo que considero es que la autorreflexion emancipatoria continúa siendo programada por el feminismo y que esa reflexión, para ser productiva en lo teórico y en lo práctico-político, habría que vincularla a una dialéctica de modernidad-postmodernidad. Desde una articulación de aquellas aportaciones de los distintos feminismos que puedan enlazar con la construcción de una racionalidad no dominadora que pueda ser instancia crítica de la normatividad, que diluci- 
de, por lo tanto, cómo y por qué el mundo ha de ser distinto de lo que es, por qué queremos una sociedad de otra manera, qué otra manera.

La propuesta de dialectica de modernidad $y$ postmodernidad incluye un pensamiento critico no solo de la Ilustración sino también del propio pensamiento y del lenguaje como necesariamente transido de dominio, cosificante. Pero, al mismo tiempo, expresa la idea de que sólo de forma inmanente a esa estructuración lingüística, a través de la cual nos humanizamos, es posible encontrar junto al dominio, la libertad, aunque sea un vacio sueño. Será un sueño vacío, será lo no-dicho, lo sin nombre, lo que es, en definitiva, "poder de hacer el bien y el mal", pero ha sido arrancada en el proceso de culturalización mismo al dominio que ese proceso representa. Ni todo es poder, ni todo es libertad. La dialectica entre Ilustración y dominio da cuenta de que en la interrelación entre razón y dominio, el mismo logos que es dominio de lo masculino sobre lo femenino, del colectivo sobre el individuo, de la burocracia sobre la masa, pone a su vez, límites a esc dominio..$^{58}$ Desde el mismo momento en que el dominio para mantener el poder se romite a la razón no tiene más remedio que limitarse a sí mismo. Ahí radican precisamente las posibilidades porque «la impotencia del siervo no puede ser ilimitada».

El feminismo pone de manifiesto que ese proceso cosificador y de dominio de la razón instrumental también es un dominio sexual. $Y$ lo es desde las mismas estructuraciones linguísticas con que se formularon los mitos hasta el propio contrato social cuya condición de posibilidad fue el "contrato sexual,$^{59}$ Por lo tanto, al realizar la critica al androcentrismo de la razón, la crítica feminista se hace desde lo que es la propia reflexión de la razón, y en ese sentido no funciona la dicotomia: la razón es masculina, el sentimiento es femenino, o el eros femenino es lo liberador como opuesto al control masculino; o la naturaleza femenina es dorninada por la razón masculina. Únicamente la reflexión sobre la misma razon instrumental-patriarcal es un más allá de ella, y por eso el feminismo al evidenciar los rasgos patriarcales de la razón va más allá. Pero ese ir más allá lo es por la reflexión y sus especificas características de crítica. La reflexión misma, al ser feminista, es antipatriarcal, pero no anti-masculina $y$, por lo tanto, femenina. Lo que el feminismo critica no es lo masculino, sino el dominio, el predominio de lo masculino sobre lo femenino, es el contrato sexual mismo.

Porque de lo que se trata es de mantener ula fuerza de la universalidad capaz de unir sin coacciones». El feminismo, al reivindicar la afirmación de las mujeres como un genérico, realiza una afirmación de sí, que puede verse en peligro si no se defiende, al mismo tiempo, el derecho de las mujeres a la universalidad, Esa afimación de sí, que significa la afirmación de la libertad de cada individuo particular y el de las pluralidades singulares, puede verse en peligro si se rechaza la universalidad por considerarla masculina y no se delimita en la razón entre razón patriarcal-instrumental (razón dominadora, pensamiento identificante) e identidad racional. Porque mientras que ael pensamiento identificante recoge la fuerza estratégica del cálculo racional que se encierra en el interés particular del individuo por su propia afirmación, en el interés particular del grupo por su propia autoafirmación", 60 la identidad racional «es una fuerza que actúa sin ejercer coacción, es la fuerza universalizadora que es núcleo de la autonomía del sujeto. Es esa racionali- 
dad por la cual el sujeto es capaz de autotrascenderse, en definitiva, la idea de humanidads. ${ }^{61}$

La propuesta de una dialéctica de modernidad y postmodernidad consistiría en trascender $y$ «reapropiarnos el universalismo democrático de la Ilustración". Reapropiación que podrá hacerse a partir de suna base común de hábitos de autodeterminación racional, de formas democráticas de decidir y de solucion de conflictos exenta de violencia». La superación de la razón una en una mutua permeabilidad de los discursos: la superación de la razón una en una interacción y juego de racionalidades plurales". 62

El núcleo, por lo tanto, de la Ilustración que constituye el ethos de la modernidad está en la unión de crítica y libertad. La definición misma de la
Ilustración en torno a las ideas de universalidad, igualdad, progreso, comportan la crítica misma de esas ideas en torno a los opuestos particularidad, diferencia, no filosofia de la historia, inconmensurabilidad de los lenguajes, no universalidad de la razón. La misma controversia entre el feminismo ilustrado y el feminismo de la diferencia sitúa en la crítica androcéntrica la misma polémica, presentándose cada uno de ellos como discurso de la modernidad y de la postmodernidad. Lo que busco clarificar es que los diferentes feminismos son prácticas y discursos que forman parte del ethos de la modernidad, es decir de la Ilustración, aunque no sean conscientes de ello. $Y$ forman parte en la medida en que son discursos que se articulan en torno a las nociones de crítica y de libertad.

\section{NOTAS}

1. C. Amorós, Barcelona, Anthropos, 1985.

2. Esta es la interpretación heideggeriana al responder a la pregunta ¿Qué significa en Kant * crfticaw? M. Heidegget; La pregunta por la cosa, Buenos Aires, Alfa, 1975, pp. 108-109.

3. Cfr. J. Habermas, Conocimiento interés, Madrid, Taurus, 1979, p. 201.

4. Me estoy refinendo al sentido de la libertad en Kant tal y como desarrollare más adelante.

5. M. Horkheimer, *Teoria Tradicional y Teora Critican, en Teoria Crutica, Buenos Aires, Amorrortu, 1974, pp. 243-249.

6. S. Sevilla, * La Teoría Crítica de la Escuela de Frankfurt y los problemas de legitimación del capitalismon, conferencia, Universidad de Cadiz, 1990.

7. M. Horkheimer, "Teoría Tradicional y Teoria Critica*, en Teoria Crfica, op cit., p. 248.

8. A. Wellmer, "La unidad no coactiva de lo multiple. Sobre la posibilidad de una nueva lectura de Adomox (trad. cast. de M. Jiménez Redondo), conferencia, Universidad de Valencia (diciembre, 1989).

9. La critica al pensamiento identificante que realizan $M$. Horkheimer $y$ Th. W. Adorno es expresada en los términos que comento por A. Wellmer en la conferencia citada.

10. A. Wellmer, op cir., p. 2.

11. Ibiden, p. 4.
12. Esta paradoja presentada por Wellmer en su interpretacion de Adorno podría caracterizarse con las palabras de $M$. Horkheimer: ese trata de un pesimismo tédrico y un optimismo prácticon.

13. A. Wellmer, op. cit., p. 4.

14. Esta sería la idea en líneas generales de J. Habermas en Teorla de la accion comunicativa, obra que representara un cambio desde la primera teoría critica. No entro, en absoluto en consideraciones sobre los problemas de la teorfa critica en general, ni de Habermas en particular. Vease para todo ello el monografico sobre Teoria Critica de Isegoria, n. 1 (mayo 1990). Véase también de M. Jiménez Redondo akant y Hegel en el pensamiento de Habernas , Introducción al libro de J. Habermas, Escritos sobre moralidad y eticidad, Barcelona, Paidós / ICE-UAB, 1991, y M. Jiménez Redondo, "Problemas de construcción". en Teoria de la acciont contunicativa, Daimon, n." 1 (1989), pp. 133-159. También: S. Sevilla, *La transformación materialista de la filosofia trascendentaly, Dainon (Universidad de Murcia). II." 1 (1989), pp. 159-175.

15. J. Habermas, Teoria de la accion comunicativa, Madrid, Taurus, 1987.

16. M. Horkheimer, Teoria Tradicional y Teoria Criticas, en Teoria Critica, op. cit., p. 249.

17. I. Kant, Crítica de la Razón Pura, Pedro Ribas (ed.), Madrid, Alfaguara, 1978, B374, p. 312. 
18. Se trata de un término acuñado para referirse a la gran polémica que hubo en el s. xv, sobre todo en Francia, en tomo al papel de las mujeres en la nueva sociedad y, en concreto, al problema de su educación. Véase $M$. Albistur y D. Armogathe, Histoire du feminisme frangaise, t. I, París, Des Femmes, 1977, p. 112 y ss.

19. F. Poulain de ja Barre, De légalité des deux sexes (1673), Paris, Fayard, 1984, p. 59. C. Amom rós, Cartesianismo y Feminismo. Olvidos de la razon, razones de los olvidos*, en Actas del seminanio permanente Feminismo e Ilustracion, 1988 . 1992, Instituto de Investigaciones Feministas, Universidad Complutense de Madrid, 1992, pp. 95-104, expone las novedades e implicaciones del "desconocido* Poulain. Hay un monográfico sobre Poulain: Corpus des Oeuvres de philosophes en langue francaise, n." I (1985), con interesantes artículos de G. Fraisse y E. Badinter. El cap. VI de la Histoire du feninisne française, op. cit., también está dedicado a Poulain de la Barre.

20. C. Amoros, "El feminismo: senda no transitada de la llustracionn, Isegorla, n." 1 (mayo, 1990), pp. 139-150. C. Molina Petit, Iustración y femintismo, tesis doctoral incdita, Universidad Complutense de Madrid, junio, 1987, en vias de publicación por esta misma Universidad. A. Valcarcel, $\alpha_{i}$ Es el Feninismo una Teoría Política?., en Sexo y Fulosofia. Sobre amujers y "poder, Barcelona, Anthropos, 1991.

21. 1. Kant, Teoria y prictica, Madrid, Tecnos, 1986 , p. 34. Se ha puesto de manifiesto la inconsistencia de Kant al respecto. Véase A. Jiménez Perona, Actas del seminatio pemantente Fentinisno e Ilustracion, 1988-1992, Instituto de Investigaciones Feministas, Universidad Complutense de Madrid, 1992, pp. 235-144.

22. M. Wollstonecraft, Vindicación de los derem chos de la mujer (1792), Madrid, Debate, 1979.

23. Olympia de Gouges, Los derechos de la mujer y de la ciudadanla* (1971), en I. Alonso y M. Belinchón, 1789-1793, La voz de las mujeres en ia Revolución Francesa (Cuadernos de quejas y otros textos), Valencia, La Sal-I.V.D., 1989, pp. 129-137.

24. Es la idea que desarrolla J.J. Rousseat en *Sofia o la mujer*, Entilio, Madrid, E,D.A.F., 1964, pp. $399-543$.

25. Madame de Stäel.

26. Simone de Beauvoire, El sezundo sexo (1949), Buenos Aires, Siglo Veinte, 1965, 1987, $2 \mathrm{v}$,

27. J.S. Mill y H.T. Mill, Ensayos sobre la igualdad sexual, Barcelona, Peninsula, 1973. El libro contiene diferentes ensayos, entre otros, el ya clásico de J.S. Mill eLa sujeción de la mujer» de 1869.

28. Simone de Beauvoire, Introducción, en $E l$ segundo sexo, op. cit., 1965. pp. 9-26. Todas las frases a las que voy aludiendo pertenecen a la introducción.
29. Como muestra del debate véase: Linda J. Nicholson (ed.), Fentinism-Postmodemism, Nueva York, Routledge, 1990. M. Hirsch y E. Fox Keller, Conflicts in Feminism, Nueva York, Routledge, 1990, S. Gunew (ed.), A Reader in Fenninist Knowledge. Nueva York, Routledge, 1991. S. Gunew (ed.), Femintst Knowledge. Critique and Construct, Nueva York, Routledge, 1990.

30. E. Grosz, aPhilosophy en S. Gunew (ed.), Feminist Knowledge. Critigue and Construct, op. cit., p. 157

31. Ibidom, p. 158 ,

32. Ibidem. Grosz se apoya en Firestone (1979) y Gatens (1983) y, aunque no la cita directamente, en Genevieve Lloyd. Véase $G$. Lloyd «El scgundo sexo a debaten, Descie el Feminismo (Madrid). n. 1 (1986), pp. 23-39, donde plantea el problema de cómo desde una perspectiva del feminismo de la diferencia, centrado en la reivindicación del cuerpo de la mujer para definirla, se podrfa llegar a alguna solución sobre el problema de la trascendencia. Sin embargo, no llega a ninguna conclusión.

33. E. Grosz, Fenimist Knowledge, op. cit., p. 159.

34. *El vindicar la igualdad legal o social nunca conllevó la indistinción de sujetos*. A. Valcarcel, Sexo y Filosofia. Sobre anujers y apoders, op. cit., p. 54.

35. G. Lloyd, Man of Reason, citado por E. Grosz en S. Gunew (ed.), A Reader in Fentinist Knowledge, op. cit. pp. 164-165.

36. C. Amoros, Hacia una critica de la razon patriarcal, op. cit., p. 103.

37. A. Valcárcel, op. cit., pp. 54-56.

38. E. Grosz, Feninist Knowiedge, op. cit., p. 165.

39. Ibidem, p. 167.

40. Ibidem.

41. S. Benhabib asumiria también esa intersubjetividad. Véase la introducción a Teora femtinista y Teoria Crítica (trad. cast. de A. Sánchez), Valencia, I.V.E. Alfons el Magnanim, 1991.

42. R. Rorty, Contingencia, tronta y solidaridad, Barcelona, Paidoss, 1991.

43. E. Grosz, Feminist Knowledge, ap, cit. p. 168.

44. Ibidem, p. 169 .

45. Ibiden.

46. C. Amorós, al feminismo: senda no transitada de la llustración, art. cit., p. 139.

47. Habermas considera la filosofía de Foucault como postmoderna. Véase El discurso filosofico de la modenidad, Madrid, Taurus, 1989, pp. 285 y ss, $y$ en líneas generales es calificada como tal. Sin embargo, el propio Foucault se vinculó a pensamientos ilustrados, críticos a su vez con la ilustración. En a ¿Qué es Ilustración?*, Pri. mer curso de 1983 en el Colegio de Francia, afirma: $Y$ me parece que la elección filosofica a la 
que nos encontramos enfrentados actualmente es la siguiente: bien optar por una filosofia critica que aparecera como una filosofía analitica de la verdad en general, bien optar por un pensamiento crítico que adoptará la forma de una ontologla de nosotros mismos, una ontología de la actualidad; esa forma de filosofia que, desde Hegel a la Escuela de Frankfurt pasando por Nietzsche y Max Weber, ha fundado una forma de reflexión en la que intento trabajar", Saber y verdad, Julia Varela y F. Alvarez Uria (cds.), Madrid, La Piqueta, 1991, p. 207.

48. M. Weber, Prólogo, en La etica protestante y el espiritu del capitalismo, Barcelona, Pentnsula, 1972 .

49. M. Foucault, "Qu'est-ce que les lumières?*, Magrazine Litteraire (abril, 1993), Gallimard, pp. $63-73$.

50. Ibidem, p. 70 .

51. Ibiden.

52. Aunque no es lo que interesa destacar aquí, habra que recordar que el programa global de Foucault de ecrítica genealogica en su diseño y arqueologica en su métodos también puede ser fructifero para el feminismo. Véase para esta cuestion Isaac D. Balbus, *Michel Foucault y cl poder del discurso feministan, en Seyla Benhabib y Drucilla Comella (eds.), Teoria feminista y teorfa critica, op. cit, pp. 169-191.

53. A. Wellmer, wa dialectica de Modernidad y Postmodemidad, Debats, n." 14 (1985), pp, 6787.

54. M. Foucault, op. cit, p. 72 ,

55. I. Kant, Crítica de la razón pum, op. cit., p. 312 .

56. M. Foucault, op. cit., p. 73.

57. Ibidem.

58. H. Brunkhorst, «Adorno: Dialéctica de la Modemidad, Seminaria sobre Adomo, Departamento de Filosofia, Universidad de Valencia (febrero 1992) (trad. cast. de M. Jimenez Redondo).

59. C. Pateman, The Sexual Cottract, California, Stanford University Press, 1988.

60. H. Brunkhorst, "Adorno: Dialéctica de la modemidadm, seminario citado.

61. Ibident.

62. A. Wellmer, sLa Dialéctica de Modemidad y Postmodemidads, art. cit, p. 86.

\title{
Elogio de la Cordura. (Una crítica al criterio de responsabilidad de Susan Wolf)
}

\author{
MIOUEL BELTRAN \\ Università degli Studi di Venezia
}

I

Sabido es que, desde los siglos xvII y XVIII, y en el debate inglés sobre la cuestión del libre albedrío, se avivó una célebre disputa en torno al asi llamado 'principio de las posibilidades alternativas' - según el cual un agente sólo puede ser considerado responsable de sus acciones si, en un sentido absoluto (esto es, simultáneamente), hubiera podido hacer otra cosa que la que efectivamente hace-. Se vieron cnvucltos en dicha disputa, de un modo primordial, los compatibilistas clásicos, desde Hobbes hasta Moore, y aún ahora se libra esa batalla (transferida a Norteamérica) entre quienes abogan de manera extremada por dicho principio -así la recurrida defensa de Chisholm (1967), o la más reciente de Van Inwagen (1983) y quienes lo denuncian como insignificante para la consideración moral - desde el artículo ya clásico de Frankfurt (1969), hasta las incisivas críticas de Dennett (1984a y $b$ ).

Los dos últimos forman parte de esa tendencia racionalista del compatibilismo actual que incluye en su nomina, 